\title{
OFERTAS SUJETAS A RESERVA: A PROPÓSITO DE LOS TÉRMINOS Y CONDICIONES EN LOS CONTRATOS CELEBRADOS POR MEDIOS ELECTRÓNICOS
}

\author{
Iñigo de la Maza Gazmuri*
}

\begin{abstract}
RESUMEN
En el derecho chileno no se ha prestado demasiada atención ni a las ofertas sujetas a reserva ni a los términos y condiciones en contratos celebrados por medios electrónicos. Un reciente caso, actualmente en tribunales, muestra la utilidad de detenerse sobre ambos temas. En las páginas siguientes me interesa mostrar cómo, en el ámbito electrónico-generalmente en la contratación a través de sitios web-el problema del carácter contractual o no de los términos y condiciones pasa por el hecho de que estos sean accesibles a los usuarios. En los hechos, la eficacia de la reserva expresa formulada por el predisponente depende de que el consumidor haya tenido un acceso claro e inequivoco a los términos y condiciones que la contenían.
\end{abstract}

\section{CONTRATACIÓN ELECTRÓNICA - DERECHO DEL CONSUMO - DERECHO PRIVADO}

\section{Offers subject to reserve: regarding the terms and conditions in contracts beld by electronic means}

\begin{abstract}
Not much attention has been in paid in Chilean Law neither to offers subject to reserve, nor to the terms and conditions in contracts beld by electronic means. A recent case, currently in court, shows the utility of studying both matters. The author tries to show how, in the e-commerce, the problem of the contract nature of the terms and conditions lies in the fact that these are accessible to users. In practice, the efficiency of the deliberate reserve expressed by the predisponent depends on that the consumer has had a clear and unmistakable access to the terms and conditions implied.
\end{abstract}

ELECTRONIC CONTRACTING - CONSUMER PROTECTION PRIVATE LAW

\footnotetext{
* Abogado, Doctor en Derecho, Profesor Investigador Facultad de Derecho de la Universidad Diego Portales, República 105, Santiago de Chile, inigo.delamaza@udp.cl

Artículo recibido el 3 de agosto de 2009 y aceptado para su publicación por el Comité Editorial el 26 de octubre de 2009.
} 
I.

\section{El $\operatorname{cas} 0^{1}$}

$\mathrm{U}$

na importante empresa dispone de un sitio web a través del cual los usuarios pueden elegir y solicitar los equipos que allí se exhiben, tal y como aparecen expuestos o bien pueden introducir ciertas modificaciones, configurándolos a su gusto según las posibilidades que se les ofrecen. Así, por ejemplo, un determinado modelo de computador portátil dispone de una cierta memoria RAM, un disco duro de determinada capacidad o ciertas garantías. Todas estas características se encuentran incluidas en el precio inicial del equipo, sin embargo, el usuario puede elegir modificar todas o algunas de esas características, incorporando otra u otras de mayor precio.

Durante el día 27 de junio de 2008, y a resultas de una falla técnica, aquellos usuarios que configuraron un cierto modelo de computador portátil, añadiéndoles un procesador de mayor poder obtuvieron una deducción en el precio inicial de su equipo. El precio inicial del equipo ascendía a $\$ 298.997$; por su parte, el costo de agregar el procesador era de $\$ 221.258$, por lo tanto, el costo final del equipo debió haber sido $\$ 520.255$. Sin embargo, por un error del sistema, el costo del procesador no se sumó al precio inicial del equipo, sino que se restó, quedando como precio final $\$ 77.739$. Este error se mantuvo durante cuatro horas, durante ese lapso de tiempo 3.150 personas solicitaron más de 7.000 computadores con esa configuración. El proveedor se negó a entregarlos.

\section{Preguntas}

La principal pregunta que se deriva de un caso como el expuesto es si el proveedor debe o no entregar los computadores. Al intentar responder esta pregunta surgen, sin embargo, otras. Las más inmediatas, me parece, son dos. En primer lugar, la obligación del vendedor depende, en este caso, del hecho que entre las partes se haya celebrado un contrato de compraventa. ¿Se perfeccionó en los hechos dicho contrato? En segundo lugar, si se asume que el contrato existió, ¿qué importancia tiene el hecho de que el sistema en vez de haber sumado al precio inicial del computador el costo del nuevo procesador lo haya restado?

El espacio que es posible asignar a este trabajo aconseja optar únicamente por una de estas dos preguntas. Mi opción es por la interrogante acerca de la existencia del contrato, es decir, la pregunta acerca de si el contrato llegó a perfeccionarse. Me parece que se trata de una cuestión interesante porque permite prestar atención a dos temas que no han sido suficientemente explorados en el derecho chileno. El primero de ellos es la oferta sujeta a reserva, el segundo de estos temas es el carácter vinculante de los "términos y condiciones" en los sitios web.

\footnotetext{
${ }^{1}$ Se trata de los hechos de Bascuñán María y otros con Dell Computer Chile Ltda., Rol 32796/2008.
} 
Mi posición es la siguiente, no cabe duda que en el caso que encabeza estas páginas el sitio web contenía una proposición de celebrar un contrato de compraventa, lo que es menos evidente es que dicha proposición deba calificarse como una oferta contractual. En la medida en que se acepte que dicha proposición se encontraba sujeta a reserva, debe considerársela más bien como una invitación a formular ofertas. Para determinar si se trata de una proposición de celebrar contratos sujeto a reserva, es necesario tener presente que existían en la página ciertos términos y condiciones de los cuales se desprendía que el proponente se reservaba el derecho de aceptar o no los pedidos de los usuarios. La pregunta que resta, entonces, es si esos términos y condiciones fueron o no aceptados por los usuarios. Si se asume que fueron aceptados, entonces, no cabe duda de que la proposición se encontraba sujeta a una reserva y que la aceptación de dicha proposición por parte de los usuarios no perfecciona el contrato; en otras palabras, si se asume que los términos y condiciones fueron aceptados por los usuarios, es necesario concluir que el contrato de compraventa no llegó a perfeccionarse.

II.

\section{Oferta sujeta a reserva}

a. Firmeza

Toda oferta contractual es una proposición de celebrar un contrato, sin embargo, no toda proposición de celebrar un contrato es una oferta contractual.

Utilizo aquí la expresión "oferta contractual" para designar un negocio jurídico de carácter unilateral a través del cual una parte propone a otra celebrar una convención en términos tales que, aceptada la proposición en forma pura y simple, la convención se entiende formada. ${ }^{2}$ Pues bien, no cualquier proposición de celebrar un contrato constituye una oferta contractual en este sentido, sino únicamente aquellas que satisfacen, copulativamente, dos requisitos: completitud o precisión y seriedad o firmeza.

Con respecto a la completitud o precisión, se exige que la oferta contractual contenga los elementos esenciales del negocio proyectado. En lo que se refiere a la firmeza o seriedad de la oferta, el requisito se entiende cumplido cuando quien formula la proposición de contrato lo hace con la intención de quedar vinculado por su aceptación. Como sugiere Díez-Picazo: "Para que exista genuina oferta, es preciso que en la declaración se produzca o manifieste una voluntad del oferente de que el contrato quede formado con la aceptación". 3 Sin que exista dicha intención no es posible hablar de oferta contractual,

${ }^{2}$ Ver, por todos, León Hurtado, A., La voluntad y la capacidad en los actos jurídicos, $4^{\mathrm{a}}$ ed., Santiago, Editorial Jurídica de Chile, 1991, p. 57.

${ }^{3}$ Díez-Picazo, L., Fundamentos del derecho civil patrimonial, I, 6a ed., Thomson Civitas, Cizur Menor (Navarra), 2007, p. 330. 
así se admite, ampliamente, tanto en la doctrina comparada como la nacional. ${ }^{4} \mathrm{La}$ misma conclusión se deriva de las normas pertinentes. ${ }^{5}$

${ }^{4}$ Señala Aubert, J.L., Notions et roles de l'offre et de l'acceptation dans la formation du contrat, L.G.D.J., París, 1970, p. 44, que la condición de firmeza de la oferta contractual es unánimemente reconocida por la doctrina francesa y añade que la exigencia de este requisito se explica por el hecho de que la aceptación de la oferta contractual entraña inmediatamente la formación del contrato. Moreno Quezada, B., La oferta de contrato, Editorial Nereo, Barcelona, 1973, p. 61, advierte que, en el Derecho español, la oferta contractual presenta dos caracteres, uno de ellos -el que interesa aquí- es "la intención del que la hace de quedar obligado por la aceptación de la misma”. El mismo autor se encarga de recordar que este requisito se ha reconocido siempre y que ya se encontraba recogido en las Partidas en los siguientes términos: "pregunta e respuesta ha menester que sea fecha en la promission por palabras, e con entendimiento de se obligar". Por su parte, treitel, G., The Law of Contract, $10^{\mathrm{a}}$ ed., Sweet \& Maxwell, Londres, 1999, p. 8, define la oferta contractual en el derecho inglés como:

“...una expresión de la voluntad de contratar en ciertos términos específicos, formulada con la intención de quedar vinculado tan pronto como dicha propuesta sea aceptada por la persona hacia quien se dirige" (la traducción es mía).

La doctrina nacional no se aleja de estas ideas. Así, por ejemplo, Domínguez Águila R., Teoría general del negocio jurídico, Editorial Jurídica de Chile, Santiago, 1980, p. 50.

señala que:

"La oferta debe ser firme, en el sentido que debe expresar una voluntad decidida de concluir un contrato, en caso de ser aceptada. No reúne tal condición aquella oferta destinada solamente a incitar a otro a contratar".

Finalmente, Claro Solar, L., Explicaciones de derecho civil chileno y comparado, t. 11, De las obligaciones II, p. 56, se refiere a la oferta expresa como aquella que tiene lugar "cuando es hecha en términos explícitos que revelen la intención inequívoca del proponente de contratar”.

${ }^{5}$ En el ordenamiento chileno es posible inducir este requisito a propósito de las normas pertinentes del Código de Comercio y reconocerlo, directamente, en el derecho uniforme de la compraventa, a través de la Convención de las Naciones Unidas sobre los Contratos de Compraventa Internacional de Mercaderías (Convención de Viena de 1980), que es ley de la República a partir del 3 de octubre de 1990.

Tratándose de las reglas del Código de Comercio, el requisito de la seriedad o firmeza de la oferta puede inducirse del juego de los artículos 101 y 105. En lo pertinente, dispone el primero que: "Dada la contestación si en ella se aprobare pura y simplemente la propuesta, el contrato queda en el acto perfeccionado..." Por su parte, el artículo 105 preceptúa en lo que es de interés aquí, que: "Las ofertas indeterminadas contenidas en circulares, catálogos, notas de precios corrientes, prospectos, o en cualquiera otra especie de anuncios impresos, no son obligatorias para el que las hace”. De la lectura de ambos artículos surge con toda naturalidad la conclusión de que únicamente si hay una declaración de voluntad emitida con la intención de quedar vinculado por la aceptación puede hablarse de una oferta contractual. (Ver Varas Braun, J.A., y Momberg Uribe, R., "La oferta en Chile: un ordenamiento, tres regímenes", en de la Maza Gazmuri, I. (editor), Temas de contratos, Ediciones de la Universidad Diego Portales, Santiago, 2006, p. 67).

Más elocuente aún es el artículo 14 de la Convención de Viena de 1980, cuyo texto dispone que:

1) La propuesta de celebrar un contrato dirigida a una o varias personas determinadas constituirá oferta si es suficientemente precisa e indica la intención del oferente de quedar obligado en caso de aceptación. Una propuesta es suficientemente precisa si indica las mercaderías y, expresa o tácitamente, señala la cantidad y el precio o prevé un medio para determinarlos.

2) Toda propuesta no dirigida a una o varias personas determinadas será considerada como una simple invitación a hacer ofertas, a menos que la persona que haga la propuesta indique claramente lo contrario.

Como puede advertirse, según lo dispuesto en el primer numeral del artículo 14 de la Convención de Viena de 1980, entonces, la propuesta de celebrar el contrato debe ser formulada con Animus contrabendi, es decir, con la intención de quedar vinculado contractualmente por su aceptación. 


\section{b. Reserva}

Si falta el requisito de la seriedad o firmeza, la proposición de contrato no produce el efecto propio de la oferta contractual, esto es, no se torna obligatoria por el hecho de la aceptación del destinatario.

En términos que resultan extrapolables para el ámbito chileno, MorENo QuEZADA distingue, para el derecho español, dos supuestos en los que falta el requisito de la seriedad o firmeza tal y como ha sido expuesto. ${ }^{6}$ El primero de ellos queda configurado por:

“Todas aquellas declaraciones de voluntad hechas sin seriedad, realizadas sencillamente por juego o jactancia y, en general, si en ellas la intención de no obligarse del que las hace resulta (...) de las circunstancias o de la naturaleza especial del asunto". 7

El segundo supuesto -que es el que presta mayor utilidad aquí- corresponde a "las ofertas en las que el autor se reserva la facultad de decidir, ya sobre la celebración misma del contrato, ya sobre la determinación de alguno de sus elementos esenciales". ${ }^{8}$ Cuando esto sucede, aun si la proposición de celebrar un contrato es completa, el hecho de que quien la formula se reserve la posibilidad de decidir si celebra o no el contrato determina que la aceptación de dicha proposición no sea suficiente para que el contrato se entienda formado. Así se acepta ampliamente en el derecho comparado. ${ }^{9}$ Existiendo una reserva:

“...la aceptación de la oferta no se mira sino como una contraproposición la cual debe ser aceptada por el autor inicial de la oferta para que el contrato se entienda celebrado". ${ }^{10}$

Finalmente, en términos de derecho comparado, la exigencia de firmeza o seriedad como un requisito de la oferta contractual se encuentra recogida también en el artículo 2.2 de los Principios UNIDROIT sobre los Contratos Comerciales y en el artículo 2:201(1)(a) de los Principios de Derecho Europeo de los Contratos.

${ }^{6}$ Moreno Quezada, La oferta de contrato., pp. 62-63.

${ }^{7}$ Ibid., p. 62.

${ }^{8}$ Ibid., p. 63.

9 Ver, por ejemplo, Larroumet, C., Les obligations, t. III, 6a ed, Le contrat. I, Conditions de formation, Economica, París, 2007, p. 225. En el ámbito del derecho inglés, Treitel (The Law of Contract., p. 11) utiliza como ejemplo de proposiciones que no constituyen ofertas aquellas en que el proponente, expresamente, señala su intención de no quedar vinculado por la aceptación del destinatario. Finalmente, en el derecho alemán, Flume (El negocio jurídico, trads. J.M. Miquel González y E. Gómez Calle, Fundación Cultural del Notariado, Madrid, 1998, pp. 752-753), se refiere a este supuesto como "la exclusión del efecto vinculante por el oferente”. Advierte el autor alemán que el $\$ 145$ del Código Civil alemán (Bürgerliches Gesetzbuch) dispone bajo el epígrafe "Vinculación a la oferta" que:

"Quien propone a otro la celebración de un contrato queda vinculado por la oferta a no ser que haya excluido la vinculación”.

${ }^{10}$ Larroumet, Les obligations, p. 225 (la traducción es mía). En el mismo sentido, Aubert, Notions et roles de l'offre, p. 137. 
En el derecho chileno, la Corte Suprema ha tenido ocasión de pronunciarse tanto respecto de la seriedad de la oferta como de las ofertas sujetas a reservas. Así, por ejemplo, en la sentencia de 16 de abril de 2008 se lee:

La oferta es un acto jurídico unilateral por el cual una persona propone a otra una determinada convención y como acto jurídico la oferta debe cumplir los requisitos de existencia y validez que establece la ley, por lo que ésta debe ser seria, es decir, que exista el propósito de producir un efecto práctico sancionado por el derecho. En el Tratado Práctico de Derecho Civil de Marcelo Planiol y Jorge Ripert, Tomo Sexto, Primera Parte, página 170 se expresa que "no existe una verdadera oferta cuando la proposición de contratar ha sido hecha como diversión o juego; de modo más práctico, siempre que su autor no ha tenido la intención de obligarse jurídicamente cuando se ha reservado su libertad, o simplemente cuando sólo ha querido iniciar preliminares de contrato que, lejos de constituir una oferta, se proponga provocarla. Pero es preciso que tal intención sea expresada o resulte de las circunstancias del caso o de los usos, de no ser así, la contraparte pudo haber creído hallarse en presencia de una oferta y la aceptación perfeccionará el contrato. ${ }^{11}$

El párrafo extractado indica dos cosas sobre las que conviene insistir: (1) la oferta debe ser seria, esto es, formulada con la intención de obligarse. (2) No es seria aquella oferta en la que su autor no ha tenido la intención de obligarse, reservándose la libertad de aceptar o no las proposiciones que reciba. Como ha señalado con acierto Aubert -conviene insistir sobre el punto-, existiendo una reserva, los roles se invierten; quien acepta se convierte en policitante y quien originalmente propuso la celebración del contrato se convierte en aceptante. ${ }^{12}$

\section{c. Ofertas sujetas a reserva y ofertas dirigidas a persona indeterminada}

La existencia de reservas anejas a la proposición de contratar puede tener un carácter tácito o expreso. El carácter de la reserva será expreso cuando quien emite la propuesta de contrato formula su renuencia a quedar obligado por la aceptación de la persona o personas hacia quienes la dirige en términos directos y explícitos. La reserva será tácita, en cambio, cuando se desprenda, indubitadamente, de las circunstancias en las cuales se formula la proposición de contratar.

El ejemplo más evidente de reservas tácitas se encuentra en las ofertas dirigidas a persona indeterminada. Así parece desprenderse del artículo 105 del Código de Comercio y del artículo 14.2 de la Convención de Viena de 1980. Así lo ha reconocido, por lo

${ }^{11}$ SF Comercial Limitada con Adexus S.A., rol No 3362-2006, número identificador Legal Publishing 38659. (Negrillas añadidas).

12 Aubert, Notions et roles de l'offre, p. 137. 
demás, la doctrina comparada ${ }^{13}$ y nacional. En esta última ha sido frecuente considerar que las ofertas dirigidas a persona indeterminada "no obligan verdaderamente al que las hace". ${ }^{14}$

La misma idea se ha afirmado, concretamente, respecto de las ofertas indeterminadas que constan en páginas web. Así, por ejemplo, Mateu de Ros señala que:

"Como regla general, la existencia de una oferta comercial genérica en una página "web” o en un portal, con su consiguiente catálogo o relación de productos y servicios en oferta, es una simple actividad de "presencia pública", que no ha de ser calificada como objeto de contrato ni producir, normalmente, ningún efecto jurídico para el proveedor (...) hasta tanto el cliente potencial o destinatario genérico de la oferta desencadene el inicio del proceso de contratación telemática a través del orden o pedido correspondiente". ${ }^{15}$

No obstante estas autorizadas opiniones, existen buenas razones para avanzar con cautela e intentar evitar las generalizaciones. Del hecho que una proposición de celebrar un contrato se dirija al público no se sigue, necesariamente, que no se trate de una oferta contractual. Así, por ejemplo, el artículo 14.2 de la Convención de Viena dispone que una oferta indeterminada "será considerada como una simple invitación a hacer ofertas, a menos que la persona que haga la propuesta indique claramente lo contrario". Una posición relativamente similar -aunque menos estricta- defiende Díez-Picazo cuando señala que:

"Para que una comunicación dirigida al público o a una generalidad o grupo de personas pueda ser considerada como una oferta de contrato hecha al público, no basta que el declarante manifieste su voluntad o su deseo de contratar, sino que es preciso que la comunicación contenga los elementos del contrato proyectado, y que el contrato quede formado para él sin más requisito que la aceptación. Por ello debe distinguirse la genuina oferta al público frente a la comunicación publicitaria, que contiene simplemente meras informaciones o invitaciones o incitaciones para que por parte del público se formulen ofertas de contrato". ${ }^{16}$

Lo relevante, entonces, no es el hecho de que la proposición se dirija a persona indeterminada, sino más bien que dicha proposición evidencie la intención del proponente de contratar con quien acepte.

13 Ver, por ejemplo, Mazeaud, H., L., y J., Lecciones de derecho civil, II-1 (Trad. Alcalá-Zamora y Castillo, L.). Editorial Jurídica Europa-América, Buenos Aires, 1960, p. 154.

${ }^{14}$ Domínguez Águila, Teoría general, p. 50.

${ }^{15}$ Mateu de Ros, R., "El consentimiento y el proceso de contratación electrónica”, en Mateu de Ros, R. y Cendoya Méndez de Vigo, J.M. (coords.), Derecho de Internet. Contratación Electrónica y Firma Digital, Aranzadi, Elcano, 2000, pp. 56-57.

${ }^{16}$ Díez-Picazo, Fundamento., p. 335. 
En un caso como el que origina las cuestiones a que se encuentran dedicadas estas páginas, la idea de que las ofertas dirigidas al público involucran una reserva tácita debe desecharse. Por una parte, en general, la forma en que se propone el contrato al público crea, en principio, la apariencia de un oferta de contrato de compraventa, no de una simple invitación a formular ofertas. ${ }^{17}$ Por otra parte, es probable que la mayoría de quienes demandaron los computadores en cuestión hayan sido consumidores y, como ha sido sugerido por Varas Braun y Momberg Uribe, tratándose de relaciones de consumo, el juego de los artículos 3 c), 12 y 13 de la Ley $\mathrm{N}^{\circ} 19.496$ :

“...permiten concluir que existe respecto del proveedor una presunción de seriedad de sus ofertas, en el sentido que el hecho de poner a disposición del público bienes o servicios relativos a su giro comercial implica per se intención de obligarse en caso de aceptación”. ${ }^{18}$

Pues bien, un caso como el que se está examinando aquí comprende una proposición de celebrar un contrato, dirigida a persona indeterminada. Como acaba de quedar dicho, de esta circunstancia no es posible desprender, necesariamente, la existencia de una reserva tácita. No obstante lo anterior, aunque no sea posible defender la presencia de una reserva tácita, es posible advertir que existió una reserva expresa que, en definitiva, determinó que el contrato de compraventa no llegara a perfeccionarse.

\section{III.}

\section{Las tratativas preliminares del contrato}

Para determinar la existencia de una reserva expresa por parte del proponente es conveniente comenzar prestando atención a las tratativas preliminares que tuvieron lugar entre éste y los usuarios de su sitio web. ${ }^{19}$

Las tratativas preliminares empiezan una vez que el usuario decide comenzar a configurar su equipo; en ese momento ha dejado de, simplemente, "vitrinear" los productos y manifiesta su voluntad de explorar la posibilidad de elaborar, discutir y concertar un posible contrato de compraventa. Concluido el proceso de configuración y cotización, el siguiente paso que debe dar el usuario consiste en emitir un "pedido" de compra del equipo individualizado. En esta segunda etapa, el usuario debe completar "opciones de envío" y "opciones de pago". Además, debe "verificar y enviar pedido”. En la pantalla

${ }^{17}$ Esto, no obstante, lo que se dirá sobre la reserva expresa.

18 Varas Braun y Momberg Uribe, "La oferta en Chile", p. 67.

${ }^{19}$ Por "tratativas preliminares" entiendo, siguiendo en esto a Díez-Picazo Fundamentos, p. 311: "los actos que los interesados y sus auxiliares llevan a cabo con el fin de elaborar, discutir y concertar el contrato". 
correspondiente a opciones de envío, el usuario debe llenar campos correspondientes a los datos de la persona a quien desea que se le envíe el equipo, informar el uso que se dará al producto solicitado y el lugar en que se utilizará. En conjunto con lo anterior, debe seleccionar una opción "Estoy de acuerdo con los Términos y condiciones de venta". En caso de que no introduzca la información que se le requiere o que elija la opción "No estoy de acuerdo con los Términos y condiciones de venta", no es posible seguir adelante con el pedido de compra del equipo. Si la información es correctamente introducida y los Términos y condiciones son aceptados, el usuario debe seleccionar el icono "Continuar" y determinar qué método de pago utilizar. Luego de ingresar los datos pertinentes según el método de pago elegido, la siguiente pantalla que se presenta al usuario corresponde a "Verificar y enviar pedido". En esta pantalla se le solicita al usuario que verifique toda la información que ha ingresado respecto del equipo seleccionado, de los datos de envío y método de pago. Para continuar, el usuario debe seleccionar un icono denominado "Enviar pedido"; una vez que es seleccionado, el usuario es informado de que su pedido ha sido enviado.

\section{Términos y condiciones}

Como ha quedado dicho, para que el usuario pueda efectuar su pedido es necesario que seleccione la opción "Estoy de acuerdo con los Términos y condiciones de venta". Una mirada a dichos términos y condiciones permite advertir que, en su número tres, bajo el título "Pedido/Contrato" dicho documento dispone que:

"Los pedidos se aceptarán por escrito, correo electrónico, teléfono o fax y sólo serán vinculantes una vez aceptados por [el proveedor] mediante la emisión de una Confirmación del Pedido por cualquiera de los medios de comunicación antes descritos. Ud. debe verificar la Confirmación del Pedido y notificarnos, inmediatamente, por escrito, cualquier error. En caso contrario, la descripción del Producto en la Confirmación del Pedido pasará a integrar este contrato y será vinculante para las partes”.

Como puede advertirse, la cláusula transcrita contiene un reserva expresa. El proponente ha manifestado su intención de no quedar vinculado por la aceptación de su propuesta. No se trata de una oferta contractual, sino de una invitación a formular ofertas.

En principio, la presencia de esta cláusula constituye un argumento suficiente para afirmar que no existió oferta contractual y que, por lo mismo, la aceptación por parte del usuario de los términos de la proposición no perfecciona el contrato de compraventa. Sin embargo, antes de llegar a esa conclusión es necesario formular algunas precisiones.

La primera de ellas se refiere a la forma en que jurídicamente deben calificarse los términos y condiciones en un supuesto como éste. Adelanto que, en mi opinión, se trata -0 , al menos, puede tratarse- de un contrato. La segunda precisión se refiere a la categoría de este contrato, sin duda, un contrato por adhesión. Finalmente, lo tercero que es necesario precisar es que se trata de un contrato celebrado por medios electrónicos. 
Las tres precisiones apuntan a determinar un mismo punto, a saber, si los términos y condiciones eran o no vinculantes para el usuario. Si lo eran, entonces el usuario aceptó una reserva expresa y, por lo mismo, no puede, lícitamente, alegar que con su aceptación se perfeccionó un contrato de compraventa. Si no lo eran, entonces parece más bien que la proposición de contrato creó una apariencia de oferta contractual y quien la formuló queda obligado contractualmente por la aceptación de la misma.

\section{La calificación jurídica de los términos y condiciones}

El uso de términos y condiciones es extremadamente frecuente en los contratos celebrados por medios electrónicos, ${ }^{20}$ ya sea para regular, por ejemplo, el uso de un determinado sitio web, ${ }^{21}$ de programas de software ${ }^{22}$ o, como sucede en el caso que se examina en estas páginas, para regular, parcialmente al menos, las tratativas preliminares del contrato. ${ }^{23}$ Pues bien, la pregunta que conviene formularse es cómo debe calificarse jurídicamente a los términos y condiciones. La respuesta, en mi opinión, es que se trata de declaraciones de una de las partes con "vocación contractual”. Es decir, se trata de la

${ }^{20}$ Ver, por ejemplo, Hillman, R., y Rachlinsky, J., "Standard-Form Contracting in the Electronic Age en New York Law Review, vol. 77, 2002, pp. 429-495; Maxeiner, J., "Standard-Terms Contracting in the Global Electronic Age: European Alternatives", en The Yale Journal of International Law, vol. 28, 2003, p. 111; Winn, J., y Bix, B., "Diverging Perspectives on Electronic contracting in the U.S. and EU”, en Cleveland State Law Review, vol. 54, 2006, pp. 175-190; Mann, R., y Siebeneicher, T., "Just One Click: The Reality of Internet Retail of Contracting”, en Columbia Law Review, vol. 108, 2008, p. 985 y Trakman, L., "The boundaries of contract law", en International Business Law Journal / (IBLJ), No 2, 2009, pp. 159-197.

${ }^{21}$ Así, por ejemplo en Ticketmaster Corp. v. Tickets.com, Inc. (2000 U.S. Dist.Lexis 4553 [C.D. Ca., marzo $27,2000)$ un sitio web ofrecía la venta de entradas para distintos eventos recreativos. El uso de la página estaba regulado por términos y condiciones de uso del sitio según los cuales la sola utilización de la página constituía la aceptación de éstos. Entre otras cosas, los términos y condiciones prohibían el uso comercial de la información contenida en la página para propósitos comerciales

${ }^{22}$ En Specht v. Netscape Communications Corp. (2001 WL 755396, 150 F. Supp. 2d 585 [S.D.N.Y., July 5, 2001], aff'd. -- F.3d - [2d Cir., Oct. 1, 2002], el demandado ofrecía en su sitio web un programa de software -Netscape Smart Download - en forma gratuita a quienes deseasen descargarlo a sus computadores. Además de la función explícita del software -descargar documentos en forma más eficiente- este cumplía una segunda tarea, enviar información sobre los documentos bajados a Netscape. Para bajar el programa a su computador el usuario únicamente debía pulsar el icono de bajada (download) y éste comenzaba a descargarse. Si el usuario se desplazaba hacia el extremo inferior de la página descubría un enlace que contenía un aviso redactado en los siguientes términos: "Por favor revise y acepte los términos del software NSD antes de descargarlo y utilizarlo". Este texto contenía un enlace que transportaba al usuario a una página separada titulada "License and Support Agreements" que notificaba al usuario que todos los productos de Netscape se encontraban regulados por contratos de licencias que debían ser aceptados por los usuarios antes de comenzar a utilizarlos. Esta página contenía además un nuevo enlace que transportaba al usuario al contrato de licencia de NSD el cual, según su texto, vinculaba al usuario a sus términos por el solo hecho de bajar el programa. Frente a la demanda, Netscape se defendió argumentando que la licencia que regulaba la utilización del producto prorrogaba la competencia para conocer de los asuntos contenciosos a un tribunal arbitral ubicado en el condado de Santa Clara, California.

${ }^{23}$ Lo que hace el número 3 de los "Términos y Condiciones Generales de Venta” es, precisamente, establecer un aspecto determinante de las tratativas preliminares del contrato, a saber, la calificación jurídica de las declaraciones de voluntad del aceptante y del declarante. 
declaración de voluntad de una de las partes que aspira a disciplinar contractualmente la relación que mantiene con la otra. Ahora bien, la expresión "vocación contractual" busca expresar que, del hecho que una parte formule una declaración con la voluntad de que su contenido forme parte de un contrato no se sigue, necesariamente, que dicha declaración sea vinculante en términos contractuales para la otra. Únicamente lo será si la otra parte ha aceptado de alguna manera dicha declaración. Esta precisión es en especial importante en este caso en el que -aceptando por el momento que los términos y condiciones constituyen un contrato- se trataría de un contrato por adhesión y celebrado por medios electrónicos. Es necesario prestar atención a ambos aspectos.

\section{Los términos y condiciones como contratos por adbesión}

En el derecho chileno la Ley $\mathrm{N}^{\circ} 19.496$ define, en su artículo 1.6, el contrato por adhesión como: "aquel cuyas cláusulas han sido propuestas unilateralmente por el proveedor sin que el consumidor, para celebrarlo, pueda alterar su contenido". Los términos y condiciones, al menos los de este caso, satisfacen los requisitos que plantea la definición. Advertido lo anterior, lo que interesa ahora es determinar en qué sentido es relevante, a efectos de la vocación contractual de estos términos y condiciones, que se trate de un contrato por adhesión.

La respuesta a esta última pregunta es que, en la medida de que se acepte que los términos y condiciones se encuentran plasmados a través de un contrato por adhesión deberán satisfacer los requisitos que el legislador impone a este tipo de negocios para que sus cláusulas se consideren vinculantes respecto del adherente.

Por razones que han sido ampliamente tratadas por la doctrina, ${ }^{24}$ el legislador manifiesta una cierta desconfianza frente a los contratos por adhesión-específicamente

${ }^{24}$ Ver, por ejemplo, para el derecho español, García Amigo, M., Condiciones generales de los contratos (civiles y mercantiles), Revista de Derecho Privado, Madrid, 1969; Castro y Bravo, F., Las condiciones generales de los contratos y la eficacia de las leyes, Instituto Nacional de Estudios Jurídicos, Madrid, 1979; Polo, E., Protección del contratante débil y condiciones generales de los contratos, Civitas, Madrid, 1990; Alfaro Águila Real, J., Las condiciones generales de la contratación. Estudio de las disposiciones generales, Civitas, Madrid, 1991; AA.VV., Las condiciones generales de la contratación y cláusulas abusivas, Civitas, Madrid, 1996; Pagador López, J., Condiciones generales y cláusulas contractuales predispuestas. La Ley de condiciones generales de la contratación de 1998, Marcial Pons, Madrid, 1999; Bercovitz Rodríguez-Cano, R. (coord.) Comentarios a la Ley de Condiciones Generales de la Contratación, Aranzadi Editorial, Elcano (Navarra), 2000; Espiau Espiau, S. (dir.), Las condiciones generales de la contratación y la Ley 7/1998, de 13 de abril, Marcial Pons, Madrid, 1999; Ballesteros Garrido, Las condiciones generales; Nieto Carol, U. (dir.), Condiciones generales de la contratación y cláusulas abusivas, LexNova, Madrid, 2000; Díez-Picazo, L. (dir.), Comentarios a la Ley sobre condiciones generales de la contratación, Civitas, Madrid, 2002; Llodrá Grimalt, F., El contrato celebrado bajo condiciones generales, Tirant Lo Blanch, Valencia, 2002; Ballugera Gómez, C., El contrato no-contrato enigma desvelado de las condiciones generales de la contratación, Colegio de Registradores de la Propiedad y Mercantiles de España, Madrid, 2006. En el derecho nacional puede consultarse Tomasello Hart, L., La contratación. Contratación tipo, de adhesión y dirigida. Autocontratación y subcontratación, Valparaíso, Edeval, 1984; López Santamaría, J., "Condiciones Generales de la Contratación y Cláusulas Abusivas”, en Cuadernos Jurídicos. Facultad de Derecho. Universidad Adolfo Ibáñez, 1996, No 4; El mismo,. "Cláusulas Contractuales Abusivas y Derecho del Consumidor", en Instituciones Modernas de Derecho Civil. Homenaje al Profesor Fernando Fueyo Laneri, Santiago, ConoSur, 1996, pp. 424-433; Veloso Valenzuela, P., "Cláusulas abusivas" en 
frente a la presencia de cláusulas abusivas- que se plasma en una serie de medidas de protección respecto de los adherentes. En el derecho chileno, el control de las cláusulas abusivas tiene lugar, generalmente, a través de tres mecanismos diversos: (1) control de inclusión, (2) reglas de interpretación favorables al consumidor y (3) control de contenido de las cláusulas. ${ }^{25}$

Respecto del control de inclusión -regulado en el artículo 17 de la Ley No 19.496-, de lo que se trata es que el texto sea "legible", lo que significa, simplemente, que el tamaño de la letra, la forma de los caracteres, su color, etc., permitan leer el documento. ${ }^{26}$ En el caso que se examina aquí no existen problemas en términos de legibilidad entendida de esta manera. ${ }^{27}$

En lo que se refiere a las reglas de interpretación, el aporte de la Ley $\mathrm{N}^{\circ} 19.496$ a este respecto es extremadamente modesto. Simplemente contiene una regla en el inciso segundo de su artículo 17, según la cual prevalecen las cláusulas agregadas por los contratantes sobre aquellas contenidas en el formulario cuando ambas resultan incompatibles. ${ }^{28}$ La regla carece de aplicación en este caso.

Finalmente, en lo que toca al control de contenido, en la Ley No 19.496, el artículo 16 de dicha norma reúne dos técnicas diversas, lo que puede denominarse "lista negra" y una "cláusula general”. La lista negra agrupa una serie de supuestos de cláusulas abusivas identificadas como tales por el legislador, en términos tales que si se presentan en el contrato el juez debe privarlas de efecto. La cláusula general, en cambio, entrega una cierta discreción al juez para evaluar si supuestos de cláusulas diversos a aquellos contenidos en la lista negra tienen o no el carácter de cláusulas abusivas. ${ }^{29}$

El número 3 de los Términos y condiciones de venta no se encuentra comprendido dentro de los supuestos de la lista negra. ${ }^{30}$ Por otra parte, para que constituyera un

Instituciones modernas de derecho civil: homenaje al profesor Fernando Fueyo Laneri. Jurídica ConoSur. Santiago, 1996, pp. 444-454; Pizarro Wilson, C., La protección de los consumidores en materia contractual, Jurídica ConoSur, Santiago, 1999.Tapia Rodríguez, M., y Valdivia Olivares, J.M., Contrato por adhesión: ley 19.496, Editorial Jurídica de Chile. Santiago: 2002; de la Maza, Gazmuri, I., "Contratos por adhesión y cláusulas abusivas. ¿Por qué el Estado y no solamente el mercado?, en Revista Chilena de Derecho Privado, Fernando Fueyo Laneri, diciembre 2003, N 1, pp. 109-148. El mismo, "El control de las cláusulas abusivas y la letra g)". Revista Chilena de Derecho Privado, Fernando Fueyo Laneri $\mathrm{N}^{\circ}$ 3, 2004, pp. 35-68.

${ }^{25}$ Ver de la Maza Gazmuri, I., "El control de las cláusulas abusivas y la letra g)", pp. 54-68.

${ }^{26}$ Un buen análisis de este requisito en Tapia Rodríguez y Valdivia Olivares, Contratos por adbesión. Ley $N^{0} 19.496$, p. 71.

${ }^{27}$ Esto, sin perjuicio de lo que se advertirá más adelante respecto del hecho que se trate de un contrato electrónico y de que se acceda a los términos y condiciones a través de hipervínculos. Ver p. 18.

${ }^{28}$ Un análisis de la regla en Tapia Rodríguez y Valdivia Olivares, Contratos por adhesión, pp. 151-157.

29 Ver de la Maza Gazmuri, I., "El control de las cláusulas abusivas y la letra g)”, pp. 57-67.

${ }^{30}$ Los supuestos son los siguientes:

“Artículo 16.- No producirán efecto alguno en los contratos de adhesión las cláusulas o estipulaciones que:

a) Otorguen a una de las partes la facultad de dejar sin efecto o modificar a su solo arbitrio el contrato o de suspender unilateralmente su ejecución, salvo cuando ella se conceda al comprador en las modalidades de venta por correo, a domicilio, por muestrario, usando medios audiovisuales u otras análogas y sin perjuicio de las excepciones que las leyes contemplen; 
supuesto de cláusula abusiva bajo el alcance de la cláusula general sería necesario que, en primer lugar, lo dispuesto en dicho número fuera contrario a la buena fe objetiva y, en segundo lugar, que produjese un desequilibrio importante, en desmedro del consumidor, en los derechos y obligaciones que se derivan del contrato. ${ }^{31}$

Para estos efectos la buena fe impone al proveedor un cierto deber de conducta referido a la forma en que diseña y presenta el contenido del contrato por adhesión. Se asume aquí que el predisponente no solamente debe satisfacer los requisitos del artículo 17 de la Ley $\mathrm{N}^{\circ} 19.496$, sino que, además debe observar todas las exigencias que imponen las convicciones éticas imperantes en el tráfico comercial, incluyendo la presentación del contenido al consumidor en términos que le resulten comprensibles a este último. ${ }^{32} \mathrm{En}$ este caso, la comprensibilidad de la cláusula no parece ser un obstáculo, un consumidor promedio debería deducir, sin problemas, de su lectura el hecho de que su aceptación de la propuesta no perfecciona el contrato.

En lo que se refiere a un desequilibrio importante, lo que se trata de determinar, en definitiva, es si atendido el contexto negocial y la economía del contrato la cláusula resulta razonable o no. ${ }^{33}$ Advertido lo anterior ¿constituye el número 3 de los Términos y condiciones de venta una estipulación razonable ${ }^{34}$ o, en cambio, se trata de una cláusula que desmedra injustificadamente la posición de los usuarios? Para hacerse cargo de esta última cuestión es relevante advertir dos peculiaridades de las tratativas preliminares de este contrato de compraventa. La primera de ellas es que el sitio web a través del cual se desarrollan las negociaciones del contrato ofrece al usuario la posibilidad de configurar su equipo, el que luego es fabricado por el proponente. La segunda es que, por parte del

b) Establezcan incrementos de precio por servicios, accesorios, financiamiento o recargos, salvo que
dichos incrementos correspondan a prestaciones adicionales que sean susceptibles de ser aceptadas o
rechazadas en cada caso y estén consignadas por separado en forma específica;
c) Pongan de cargo del consumidor los efectos de deficiencias, omisiones o errores administrativos,
cuando ellos no le sean imputables;
d) Inviertan la carga de la prueba en perjuicio del consumidor;
e) Contengan limitaciones absolutas de responsabilidad frente al consumidor que puedan privar a
éste de su derecho a resarcimiento frente a deficiencias que afecten la utilidad o finalidad esencial del
producto o servicio".
31 La letra g) del artículo 16 dispone [No producirán efecto alguno en los contratos de adhesión las cláusulas o estipulaciones que]:

"En contra de las exigencias de la buena fe, atendiendo para estos efectos a parámetros objetivos, causen en perjuicio del consumidor, un desequilibrio importante en los derechos y obligaciones que para las partes se deriven del contrato. Para ello se atenderá a la finalidad del contrato y a las disposiciones especiales o generales que lo rigen. Se presumirá que dichas cláusulas se encuentran ajustadas a exigencias de la buena fe, si los contratos a que pertenecen han sido revisados y autorizados por un órgano administrativo en ejecución de sus facultades legales".

32 Ver de la Maza Gazmuri, I., "El control de las cláusulas abusivas y la letra g)”, pp. 59-64.

33 Me he referido con mayor detalle a este requisito en Ibid., pp. 52-53 y 64.

${ }^{34}$ En un fallo de 21 de septiembre de 2007 (Juan Pablo Camus Valverde con Comercializadora Aldo Mantagua S.A.”, rol No 37246-2007, $\mathrm{N}^{\circ}$ Legal Publishing 37182), la Corte de Apelaciones de Santiago señaló que para determinar si existe un grave desequilibrio deben considerarse las expectativas razonables del consumidor. 
proponente el procedimiento se encuentra completamente automatizado. Con respecto a la posibilidad de configuración, es el usuario quien decide un porcentaje significativo de las características del equipo y, a través de su pedido, encarga su fabricación al proponente. En un modelo de negocios en que se trabaja fabricando ordenadores a pedido y que el éxito de dicha fabricación no depende totalmente del fabricante (así, por ejemplo, la disponibilidad de las partes del computador es función de la oferta y demanda actuales a nivel mundial) parece sensato que el fabricante se reserve el derecho de decidir si, en un determinado momento, se encuentra en condiciones de fabricar el equipo solicitado. Por otra parte, un procedimiento automatizado entraña ciertos riesgos, como ya se ha visto, en el caso con que comienza este trabajo, existió un error de cálculo por parte del proveedor. ${ }^{35} \mathrm{El}$ hecho de que se trate de un procedimiento automatizado le impidió a éste advertir dicho error, sin embargo, el mismo fue descubierto al procesar las solicitudes de los usuarios que habían efectuado los respectivos pedidos. Dicho error se les comunicó con toda prontitud. La posibilidad de revisar los pedidos permitió al proveedor detectar este tipo de errores y corregirlos, resguardando, de esta manera, una adecuada formación del consentimiento. La cláusula parece, entonces, razonable, sin que se advierta un desmedro injustificado de la posición del consumidor.

\section{Los términos y condiciones como contrato celebrado por medios electrónicos}

En general, puede hablarse de un contrato celebrado por medios electrónicos cuando tanto la oferta como la aceptación fueron emitidas electrónicamente. ${ }^{36}$ Cuando la oferta se emite a través de una página web y la aceptación se produce en dicho sitio, entonces existe un supuesto de contrato electrónico. ${ }^{37}$

Que se trate de un contrato celebrado por medios electrónicos tiene importancia para efectos de este caso. La Ley $\mathrm{N}^{\circ} 19.496$ establece, en su artículo $12 \mathrm{~A}$, algunas obligaciones -aunque en términos técnicos se trataría, más bien, de cargas- ${ }^{38}$ especiales al proveedor, según el tenor del precepto mencionado:

35 Ver p. 1.

${ }^{36}$ En el derecho chileno, el artículo 2 a) de la ley $\mathrm{N}^{\circ} 19.799$ sobre documentos electrónicos, firma electrónica y servicios de certificación de dicha firma define electrónico como "característica de la tecnología que tiene capacidades eléctricas, digitales, magnéticas, inalámbricas, ópticas, electromagnéticas u otras similares".

${ }^{37}$ Respecto de la distinción entre contratos electrónicos celebrados a través de Internet y otras modalidades de contratación informática puede consultarse Mateu de Ros, "El consentimiento”, pp. 42-43.

38 Utilizo aquí la expresión carga como "la necesidad de adoptar una cierta conducta si se quiere lograr un cierto resultado” (Peñailillo Arévalo, D., Obligaciones. Teoría general y clasificaciones. La resolución por incumplimiento, Editorial Jurídica de Chile, Santiago, 2003, p. 80. Sobre esto puede consultarse, además, Díez-Picazo, L., Fundamentos de derecho civil patrimonial, vol. II, Las relaciones obligatorias, $6^{a}$ ed., Thomson Civitas, Cizur Menor (Navarra), 2008, pp. 134-138. Se trataría de cargas en la medida que, si el proveedor aspira a que sus términos y condiciones vinculen contractualmente al consumidor debe adoptar ciertas conductas que garanticen al consumidor un acceso claro, comprensible e inequívoco. 
En los contratos celebrados por medios electrónicos, y en aquellos en que se aceptare una oferta realizada a través de catálogos, avisos o cualquiera otra forma de comunicación a distancia, el consentimiento no se entenderá formado si el consumidor no ha tenido previamente un acceso claro, comprensible e inequívoco de las condiciones generales del mismo y la posibilidad de almacenarlos o imprimirlos.

La sola visita del sitio de Internet en el cual se ofrece el acceso a determinados servicios, no impone al consumidor obligación alguna, a menos que haya aceptado en forma inequívoca las condiciones ofrecidas por el proveedor.

Una vez perfeccionado el contrato, el proveedor estará obligado a enviar confirmación escrita del mismo. Ésta podrá ser enviada por vía electrónica o por cualquier medio de comunicación que garantice el debido y oportuno conocimiento del consumidor, el que se le indicará previamente. Dicha confirmación deberá contener una copia íntegra, clara y legible del contrato.

Existe una diferencia -aunque sea de grado- entre los contratos por adhesión que suelen celebrarse en el mundo del papel y aquellos que tienen lugar en el entorno electrónico. Tratándose del mundo del papel, el problema suele ser que el contenido del contrato sea legible y comprensible. En el entorno electrónico se añade otra dificultad y es el conocimiento por parte del adherente de la existencia del contrato en cuestión. ${ }^{39}$ Esta es precisamente la dificultad que impregna este caso; el problema no es si los términos y condiciones eran o no legibles y comprensibles - lo eran- sino más bien si el consumidor tuvo una posibilidad razonable de acceder a ellos. El caso que se examina en este trabajo encaja en el inciso primero del artículo $12 \mathrm{~A} .{ }^{40}$ Según dicho precepto,

${ }^{39}$ Así, por ejemplo en Specht v. Netscape, ver infra nota 23.

${ }^{40}$ El segundo inciso apunta a una situación, se trata de evitar ciertas prácticas relativamente difundidas entre quienes ofrecen productos y servicios a través de páginas web según las cuales se asume que, por el solo hecho de que un sitio web disponga de términos y condiciones, éstos vinculan al usuario, no obstante el hecho de que no se exigía ningún acto del consumidor que evidencie su aceptación de dichos términos y condiciones.

Un caso estadounidense permitirá ilustrar este supuesto. Se trata de Pollstar v. Gigmania. (2000 WL 33266437 [E.D. Cal. Oct. 17, 2000]. Pollstar, el demandante, mantenía un sitio web que contenía información que, según se afirmaba ahí, se encontraba protegida por derechos de autor. La página web contenía un enlace que, de pulsarlo, transportaba al usuario a una página web distinta que contenía el texto completo del contrato de licencia, el que, supuestamente, resultaba vinculante para cualquier usuario de la página. Cabe advertir que para utilizar los servicios de la página web no se requería realizar ningún acto de aceptación respecto de los términos de la licencia o siquiera leerlos. Los demandados copiaron parte de la información del sitio. Pollstar los demandó por incumplimiento del contrato de licencia y el argumento de la defensa fue que no había existido contrato por falta de consentimiento sobre sus términos. Aunque la corte denegó la defensa de los demandados, manifestó sus dudas sobre los contratos browse en los siguientes términos:

La corte está de acuerdo con el demandado en que al visitar el sitio únicamente, muchos de sus usuarios podrían no advertir la existencia de un contrato de licencia. El aviso del contrato se encuentra en un pequeño texto gris sobre un fondo gris... No se han reportado casos que resuelvan la ejecución forzosa de contratos de licencia browse [browse wrap licence]... Si bien la corte está de acuerdo (con el demandado) que el usuario no es confrontado inmediatamente con la noticia del contrato de licencia, esto no elimina [dispose] el alegato (del demandante) de incumplimiento contractual. La corte tiene 
el consentimiento no se entenderá formado si el consumidor no tuvo "un acceso claro, comprensible e inequívoco de las condiciones generales del mismo y la posibilidad de almacenarlos o imprimirlos". En otras palabras, los Términos y condiciones de venta -y por lo tanto la reserva expresa del proponente- únicamente vinculan al consumidor si este tuvo un acceso "claro, comprensible e inequívoco" a ellos. ${ }^{41}$

Para determinar si existió o no este acceso, convendrá volver sobre las tratativas preliminares del contrato y revisar la forma en que se informó al usuario la presencia de dichos términos y condiciones. Antes de enviar su pedido el usuario debía completar cierta información respecto al destinatario del pedido y luego, bajo el título "Términos y condiciones de venta", resaltado en la pantalla, se le ofrecían dos opciones: "Estoy de acuerdo con los Términos y condiciones de venta" y "No estoy de acuerdo con los Términos y condiciones de venta". Inmediatamente debajo de estas dos opciones se encontraba un siguiente aviso:

"Los términos y condiciones de venta contienen información muy importante acerca de sus derechos y obligaciones además de limitaciones que podrían aplicársele. Toda norma obligatoria del consumidor que sea aplicable no se ve afectada por estas Condiciones. Lea la sección detenidamente”.

Únicamente si el usuario seleccionaba la primera de las dos opciones - "Estoy de acuerdo con los Términos y condiciones de venta”- era posible continuar con el procesamiento del pedido.

La expresión "Términos y condiciones de venta" estaba "hipervinculada". ${ }^{42} \mathrm{Si}$ el usuario seleccionaba el hipervínculo, se le dirigía a otra sección del sitio web, en cuyo extremo superior aparecía un nuevo hipervínculo "Términos y condiciones de venta”. Una vez seleccionado este último hipervínculo, se desplegaba ante el usuario el clausulado de los Términos y condiciones.

Pues bien, lo primero que es necesario advertir es que el artículo $12 \mathrm{~A}$ de la Ley $\mathrm{N}^{\circ} 19.496$ no exige que el consumidor haya accedido a las condiciones del contrato, sino que, cosa distinta, exige que el consumidor haya dispuesto de un acceso claro, comprensible e inequívoco. De manera que si existe esta especie de acceso, el hecho

dudas acerca de declarar la invalidez e inejecutabilidad de contrato de licencia browse esta vez (la traducción es mía).

En general, los tribunales estadounidenses han estimado que en supuestos como éste no existe contrato. Ver Mann y Siebeneicher “Just One Click”, pp. 990-993.

${ }^{41}$ Para este caso al menos el requisito de que dichos términos pudieran ser almacenados o impresos no presenta problema.

${ }^{42}$ Utilizo aquí la expresión "hipervínculo" como una traducción de byperlink, es decir, un elemento contenido en un documento electrónico que se encuentra vinculado a otro espacio del mismo documento a otro documento completamente distinto. En este caso el vínculo se establecía entre dos porciones diversas del sitio web del proveedor, en una de ellas - la que se encontraba el hipervínculo- correspondía a los campos que debían ser llenados para enviar el pedido. La segunda porción correspondía a las regulación de la actividad del proveedor, por ejemplo, uso de datos personales del usuario y términos y condiciones de venta”. 
de que el consumidor haya o no accedido al contenido del contrato es jurídicamente irrelevante. Esta conclusión parece evidente por dos razones. La primera de ellas es que de la función tutelar que es posible reconocer a las normas que disciplinan las relaciones de consumo, no es posible desprender que el ordenamiento jurídico ha renunciado a tratar a los consumidores como personas capaces y, por lo tanto, imputables por sus decisiones. ${ }^{43}$ De esta manera, si un consumidor recibe información suficiente sobre la presencia de los términos y condiciones y su importancia y decide no leerlos, los riesgos de esta decisión deben imputársele. En otras palabras, los términos y condiciones lo vinculan. La segunda razón se encuentra en la Ley $\mathrm{N}^{\circ}$ 19.496, específicamente en la carga de información sobre las condiciones del contrato que impone al consumidor el

${ }^{43}$ Esta es una idea sobre la que conviene insistir. Como acertadamente han advertido Malaurie, Aynès y Stoffel-Munck (Les obligations, $3^{\mathrm{a}}$ ed., Defrénois, París, 2003, p. 191) la vocación del derecho no ha sido jamás, ni debe llegar a ser, convertir a los agentes jurídicos en incapaces. Esta afirmación no es, desde luego, ajena a las normas que regulan las relaciones de consumo. Una breve mirada a la legislación comunitaria europea -a la cual ha interesado especialmente la protección de los consumidores- permite advertirlo. Así, por ejemplo, el artículo 2.3 de la Directiva 99/44/CE, que regula la conformidad del bien mueble en el contrato de compraventa, dispone:

"Se considerará que no existe falta de conformidad a efectos del presente artículo si en el momento de la celebración del contrato el consumidor tenía conocimiento de este defecto o no podía fundadamente ignorarlo, o si la falta de conformidad tiene su origen en materiales suministrados por el consumidor". En un sentido similar, el artículo 5.1 de la Directiva 2001/95/CE relativa a seguridad de los productos:

"Dentro de los límites de sus respectivas actividades, los productores proporcionarán a los consumidores información adecuada que les permita evaluar los riesgos inherentes a un producto durante su período de utilización normal o razonablemente previsible, cuando éstos no sean inmediatamente perceptibles sin avisos adecuados, a fin de que puedan precaverse de dichos riesgos".

Lo que se desprende del artículo 2.3 de la Directiva 99/44/CE es que si el consumidor conocía o debía conocer el defecto, no puede, después, alegar falta de conformidad. Por su parte, el artículo 5.1 de la Directiva 2004/95/CE impone el deber de proporcionar a los consumidores información sobre los riesgos de un producto, salvo que éstos sean perceptibles. En ambos preceptos se impone al consumidor un cierto nivel de diligencia para gozar de la protección que le brindan las respectivas Directivas.

Algo similar han considerado los tribunales españoles. Así, por ejemplo, una SAP de La Coruña de 11 de marzo de 2005 sobre un contrato de préstamo al consumo ha resuelto que:

“(...) no puede extenderse la protección al consumidor hasta el punto de considerarlo un incapaz. Ciertamente en los últimos años, y mayoritariamente por imposición de Directivas comunitarias, se ha desarrollado en España una legislación muy proteccionista de los consumidores y usuarios. Pero esta normativa tuitiva no puede llevarse a extremos tales que supongan, en la práctica, privar de derechos civiles a los ciudadanos, convirtiéndolos en auténticos incapaces, hasta el punto de que el otorgamiento de un contrato carezca de todo valor jurídico simplemente porque el consumidor afirme "que no lo leyó", o que no sabía lo que hacía. Esto puede llevar a la defenestración de las relaciones negociales. Son personas mayores de edad, con plenos derechos civiles, y por lo tanto responsables de sus contrataciones. Las normas indicadas tienen la finalidad de exigir mayores garantías a los empresarios y proveedores, no dejarlos inermes ante suministros defectuosos, o que no se abuse de la posición dominante del proveedor. Pero nunca exonerarlos de lo que pueden ser malos negocios o errores en la toma de decisiones personales".

Lo que subyace a las Directivas citadas y a la SAP de la Coruña es una idea central en el derecho de contratos que no debe olvidarse -aunque sí matizarse- en las relaciones de consumo y otras similares: los contratantes no deben ser tratados como incapaces, liberándolos de responsabilidad por sus decisiones. Esto es lo que suele denominarse el principio de la autorresponsabilidad (vuelvo sobre él en la siguiente nota). 
artículo 3 b) de dicha ley. En mi opinión, este precepto plasma el principio de autorresponsabilidad en la ley citada. ${ }^{4}$

¿Era, entonces, accesible la información acerca de los términos y condiciones? Para responder a esta pregunta conviene desagregarla en dos cuestiones distintas. La primera de ellas consiste en determinar si el usuario tuvo noticia acerca de la existencia de términos y condiciones; la segunda cuestión es si pudo acceder a ellos. Con respecto a la primera cuestión, la respuesta, en mi opinión al menos, es que el usuario tuvo conocimiento de la existencia de los términos y condiciones y, si no lo tuvo, su ignorancia es inexcusable. El proceso de envío del pedido exigía al usuario un acto de aceptación inequívoco de los términos y condiciones. A partir de ese momento el consumidor no puede, legítimamente, ignorar la existencia de dichos términos. ${ }^{45}$

La segunda cuestión que se trata de responder es si el consumidor puede alegar legítimamente que, aun teniendo conocimiento de la existencia de términos y condiciones no fue capaz de acceder a ellos. Al margen de si se acepte o no que los usuarios de Internet son consumidores más "sofisticados" que sus pares que únicamente contratan en el mundo del papel, ${ }^{46}$ lo que interesa advertir aquí es si los consumidores que optaron

${ }^{44}$ En general, se acepta tanto por los autores (ver, por todos, Cariota Ferrara, L., El negocio jurídico, trad. M. Albaladejo, Aguilar, Madrid, 1959, p. 53; Betti, E., Teoría general del negocio jurídico, $2^{\mathrm{a}}$ ed, trad. A. Martín Pérez, Editorial Revista de Derecho Privado, Madrid, 1959, p. 326; Castro y Bravo, F. de, El negocio jurídico, Instituto Nacional de Estudios Jurídicos, Madrid, 1971, p. 116, refiriéndose al "principio de responsabilidad negocial", que exige: "valorar la buena fe de la conducta y el modo de cumplir según ella los deberes de informar y de informarse"; y Albaladejo, M., Derecho civil, t. I, Introducción y parte general. $17^{\mathrm{a}}$ ed. Edisofer, Madrid, 2006. I, $17^{\mathrm{a}}$ ed., p. 622) que las partes deben comportarse responsablemente durante la negociación de un contrato. La idea es que como corolario de la libertad que el ordenamiento jurídico concede a las personas de vincularse a través del ejercicio de su autonomía, también las hace responsables de los efectos de sus actos. (Sobre esta idea puede consultarse Betti (Teoría general, p. 125) quien ha sugerido que "[t]oda la dialéctica del negocio jurídico se apoya sobre esta antinomia entre libertad, que es antes, y autorresponsabilidad que viene después”. Una idea, por lo demás, antigua: "Contractus ab inito est voluntas, ex post facto nesessitatis").

Sin embargo, conviene hacer una precisión, pues se puede ser responsable en, al menos, dos sentidos distintos (ver Cariota Ferrara, El negocio jurídico, p. 53. Ver, también, Pietrobon, V. (El error en la doctrina del negocio jurídico, trad. M. Alonso Pérez, Editorial Revista de Derecho Privado, Madrid, 1971, pp. 268-269), relacionando, en sede de error, la autorreponsabilidad con la protección de la confianza de la parte que recibe la declaración). De una parte, frente a terceros, en cuyo caso la responsabilidad se traduce en una obligación de indemnizar los perjuicios causados. De otra, se puede ser responsable en el sentido de que las declaraciones de voluntad que formula una persona le son imputables. A este segundo sentido puede denominársele "autorresponsabilidad" y, en sede de negociaciones de un contrato, significa que, bajo ciertas condiciones, la persona que celebra un contrato debe "sufrir los efectos del negocio que realiza" (loc. cit.), aun cuando no los desee. Así sucede, por ejemplo, con el error inexcusable, el dolo bueno y la reserva mental.

45 En el ámbito estadounidense suele denominarse a este tipo de negocios "clickwrap contracts" y se les reconoce carácter contractual.

${ }^{46}$ Ver, por ejemplo, Hillman y Rachlinsky, "Standard-Form Contracting”, p. 478. En el ámbito chileno, un temprano estudio de 1999 realizado por la Universidad de Chile durante ese año mostraba que un 75,5\% de los usuarios de Internet en Chile tenían menos de 35 años, de los mayores de 18 años un 64,5\% eran hombres, prácticamente un $70 \%$ de los usuarios mayores de 18 años tenía acceso a un buen nivel educacional y menos de un tercio de los usuarios mayores de 18 años poseían ingresos familiares inferiores a quinientos mil pesos (ver Demografía y comportamiento de los usuarios chilenos en Internet. Universidad de Chile. Disponible 
por configurar los equipos, reemplazando el procesador y que luego efectuaron un pedido se encontraban o no en condiciones de acceder a los términos y condiciones. La respuesta, en mi opinión, es que sí; la razón es que acceder a los términos y condiciones implicaba, únicamente, seleccionar dos hipervínculos, una tarea en extremo sencilla para quien ya había configurado -a través de varias operaciones- el computador objeto de su pedido.

A lo largo de este trabajo he examinado dos temas: la oferta con reserva y los términos y condiciones en los contratos por adhesión celebrados por medios electrónicos. Mi opción ha sido explorarlos a propósito de un caso que los vincula. Es tiempo ahora de presentar las conclusiones.

La primera de ellas es que una proposición de contrato sujeta a reserva no produce los mismos efectos de una oferta contractual. Los papeles se invierten, el aceptante se transforma en proponente y el proponente es quien debe decidir si acepta o no la oferta.

La segunda conclusión es que las proposiciones dirigidas a persona indeterminada pueden o no constituir ofertas contractuales, dependerá de si satisfacen o no los requisitos de este último tipo de propuesta de celebración de contrato.

La tercera es que cuando dichas proposiciones se dirigen a consumidores, por regla general, involucran una oferta contractual. No existe -salvo situaciones excepcionalesuna reserva tácita por el hecho de dirigir la oferta a persona indeterminada.

No obstante lo anterior, en este caso existió una reserva expresa de la cual se infiere, con toda claridad, que el proponente no deseaba quedar vinculado por la aceptación del destinatario. La pregunta es si esa reserva resultaba o no oponible al destinatario, y el interés de la pregunta surge porque la reserva se encontraba en los términos y condiciones.

La cuarta conclusión es que, en el entorno electrónico, los términos y condiciones en los contratos celebrados por medios electrónicos poseen una vocación contractual, es decir, el predisponente los establece con el objetivo de que se integren como regulación contractual de su relación con el adherente.

La quinta conclusión es que la concreción de dicha vocación contractual depende de que dichos términos y condiciones satisfagan los requisitos propios de los contratos por adhesión celebrados por medios electrónicos.

Finalmente, la sexta conclusión se refiere a este caso y es que la reserva contenida en los términos y condiciones de venta era oponible a los usuarios, de manera que la proposición de celebrar contrato no constituyó una oferta contractual. Por lo mismo, su

en http://www.facea.uchile.cl/uca/estudios/1999/usuarios /texto2.htm. Visitado 03/04/2000). Las estimaciones de la Cámara de Comercio de Santiago (CCS) correspondientes al año 2001 resultan consistentes con las anteriores, aunque advierten una relativa democratización a partir del año 1999. (Ver La Economía Digital en Chile 2002. Centro de Estudios de la Economía Digital. Cámara de Comercio de Santiago. Junio 2002). 
aceptación por parte de los destinatarios no determinó el surgimiento de un contrato de compraventa.

\section{BIBLIOGRAFÍA}

AA.VV., Las condiciones generales de la contratación y clausulas abusivas, Civitas, Madrid, 1996.

Albaladejo, M., Derecho civil, t. I, Introducción y parte general. $17^{\mathrm{a}}$ ed. Edisofer, Madrid, 2006. I, $17^{\mathrm{a}}$ ed.

Alfaro Águila Real, J., Las condiciones generales de la contratación. Estudio de las disposiciones generales, Civitas, Madrid, 1991.

Aubert, J.L., Notions et roles de l'offre et de l'acceptation dans la formation du contrat, L.G.D.J., París, 1970.

Ballesteros Garrido, Las condiciones generales; Nieto Carol, U. (dir.), Condiciones generales de la contratación y cláusulas abusivas, LexNova, Madrid, 2000; Díez-Picazo, L. (dir.), Comentarios a la Ley sobre condiciones generales de la contratación, Civitas, Madrid, 2002.

Ballugera Gómez, C., El contrato no-contrato enigma desvelado de las condiciones generales de la contratación, Colegio de Registradores de la Propiedad y Mercantiles de España, Madrid, 2006.

Bercovitz Rodríguez-Cano, R. (coord.) Comentarios a la Ley de Condiciones Generales de la Contratación, Aranzadi Editorial, Elcano (Navarra), 2000.

BetTi, E., Teoría general del negocio jurídico, $2^{a}$ ed, trad. A. Martín Pérez, Editorial Revista de Derecho Privado, Madrid, 1959.

Cámara de Comercio de Santiago, La Economía Digital en Chile 2002. Centro de Estudios de la Economía Digital. Cámara de Comercio de Santiago. Junio 2002.

Cariota Ferrara, L., El negocio jurídico, trad. M. Albaladejo, Aguilar, Madrid, 1959.

Castro y Bravo, F. De, El negocio jurídico, Instituto Nacional de Estudios Jurídicos, Madrid, 1971.

Castro y Bravo, F., Las condiciones generales de los contratos y la eficacia de las leyes, Instituto Nacional de Estudios Jurídicos, Madrid, 1979.

Claro Solar, L., Explicaciones de derecho civil chileno y comparado, vol. V., t. 11, De las obligaciones II, Editorial Jurídica de Chile, Santiago, 1979.

De la Maza, Gazmuri, I., "Contratos por adhesión y cláusulas abusivas ¿Por qué el Estado y no solamente el mercado?, en Revista Chilena de Derecho Privado, Fernando Fueyo Laneri, diciembre $2003, \mathrm{~N}^{\circ} 1$.

De la Maza, Gazmuri, I., "El control de las cláusulas abusivas y la letra g)". Revista Chilena de Derecho Privado, Fernando Fueyo Laneri $\mathrm{N}^{\circ}$ 3, 2004.

Díez-PiCazo, L., Fundamentos del derecho civil patrimonial, I, $6^{\mathrm{a}}$ ed., Thomson Civitas, Cizur Menor (Navarra), 2007.

DíEz-Picazo, L., Fundamentos de derecho civil patrimonial, vol. II, Las relaciones obligatorias, $6^{a}$ ed., Thomson Civitas, Cizur Menor (Navarra), 2008.

Domínguez Águila, R., Teoría general del negocio jurídico, Editorial Jurídica de Chile, Santiago, 1980.

Espiau Espiau, S. (dir.), Las condiciones generales de la contratación y la Ley 7/1998, de 13 de abril, Marcial Pons, Madrid, 1999.

Flume, El negocio jurídico, trads. J.M. Miquel González y E. Gómez Calle, Fundación Cultural del Notariado, Madrid, 1998.

García Amigo, M., Condiciones generales de los contratos (civiles y mercantiles), Revista de Derecho Privado, Madrid, 1969. 
Hillman, R. y Rachlinsky, J., "Standard-Form Contracting in the Electronic Age en New York Law Review, vol. 77, 2002.

Larroumet, C., Les obligations, t. III, $6^{a}$ ed, Le contrat. I, Conditions de formation, Economica, París, 2007.

León Hurtado, A., La voluntad y la capacidad en los actos jurídicos, $4^{\mathrm{a}}$ ed., Santiago, Editorial Jurídica de Chile, 1991.

Llodrá Grimalt, F., El contrato celebrado bajo condiciones generales, Tirant Lo Blanch, Valencia, 2002.

López Santamaría, J., “Condiciones Generales de la Contratación y Cláusulas Abusivas”, en Cuadernos Jurídicos. Facultad de Derecho. Universidad Adolfo Ibáñez, 1996, N 4.

López Santamaría, J., "Cláusulas Contractuales Abusivas y Derecho del Consumidor", en Instituciones Modernas de Derecho Civil. Homenaje al Profesor Fernando Fueyo Laneri, Santiago, ConoSur, 1996.

Mann, R. y Siebeneicher, T., "Just One Click: The Reality of Internet Retail of Contracting”, en Columbia Law Review, vol. 108, 2008.

Malaurie, Ph., Aynès, L. y Stoffel-Munck, Ph., Les obligations, $3^{a}$ ed., Defrénois, París, 2003.

Mateu De Ros, R., "El consentimiento y el proceso de contratación electrónica", en Mateu De Ros, R. y Cendoya Méndez de Vigo, J.M. (coords.), Derecho de Internet. Contratación Electrónica y Firma Digital, Aranzadi, Elcano, 2000.

Maxeiner, J., "Standard-Terms Contracting in the Global Electronic Age: European Alternatives", en The Yale Journal of International Law, vol. 28, 2003.

Mazeaud, H., L. y J., Lecciones de derecho civil, II-1 (Trad. Alcalá-Zamora y Castillo, L.) Editorial Jurídica Europa-América, Buenos Aires, 1960.

Moreno Quezada, B., La oferta de contrato, Editorial Nereo, Barcelona, 1973.

PAgador López, J., Condiciones generales y cláusulas contractuales predispuestas. La Ley de condiciones generales de la contratación de 1998, Marcial Pons, Madrid, 1999.

Peñailillo Arévalo, D., Obligaciones. Teoría general y clasificaciones. La resolución por incumplimiento, Editorial Jurídica de Chile, Santiago, 2003.

Pietrobon, V. (El error en la doctrina del negocio jurídico, trad. M. Alonso Pérez, Editorial Revista de Derecho Privado, Madrid, 1971.

Pizarro Wilson, C., La protección de los consumidores en materia contractual, Jurídica ConoSur, Santiago, 1999.

Polo, E., Protección del contratante débil y condiciones generales de los contratos, Civitas, Madrid, 1990.

Tapia Rodríguez , M. y Valdivia Olivares, J.M., Contrato por adhesión: ley 19.496, Editorial Jurídica de Chile. Santiago: 2002.

Trakman, L., "The boundaries of contract law", en International Business Law Journal / (IBLJ), $\mathrm{N}^{\circ} 2,2009$.

Tomasello Hart, L., La contratación. Contratación tipo, de adhesión y dirigida. Autocontratación y subcontratación, Valparaíso, Edeval, 1984.

Treitel, G., The Law of Contract, $10^{a}$ ed., Sweet \& Maxwell, Londres, 1999.

Varas Braun, J.A. y Momberg Uribe, R., "La oferta en Chile: un ordenamiento, tres regímenes, en de la Maza Gazmuri, I. (editor), Temas de contratos, Ediciones de la Universidad Diego Portales, Santiago, 2006.

Veloso Valenzuela, P., "Cláusulas abusivas" en Instituciones modernas de derecho civil: homenaje al profesor Fernando Fueyo Laneri. Jurídica ConoSur. Santiago, 1996.

Winn, J., y BIX, B., "Diverging Perspectives on Electronic contracting in the U.S. and EU”, en Cleveland State Law Review, vol. 54, 2006. 
